Review

\title{
Treatment of Prosthetic Joint Infection with Debridement, Antibiotics and Irrigation with Implant Retention - a Narrative Review
}

\author{
Ricardo Sousa ${ }^{1,3^{*}}$, Miguel Araújo Abreu ${ }^{2,3^{*} \bowtie}$ \\ 1. Department of Orthopaedics, Centro Hospitalar do Porto, Porto, Portugal \\ 2. Department of Infectious Diseases, Centro Hospitalar do Porto, Porto, Portugal \\ 3. Grupo TrofaSaude - Hospital em Alfena, Valongo, Portugal \\ * Porto Bone and Joint Infection Group (GRIP), Centro Hospitalar do Porto and Grupo TrofaSaude - Hospital em Alfena, Portugal \\ $\square$ Corresponding author: Ricardo Sousa. Email: contacto@ricardosousaortopedia.pt. Department of Orthopaedics, Centro Hospitalar do Porto - Hospital de \\ Santo António, Largo Professor Abel Salazar, 4099-001 Porto, Portugal. Tel. (00351)222 077500 - Fax. (00351)222 087632 \\ (c) Ivyspring International Publisher. This is an open access article distributed under the terms of the Creative Commons Attribution (CC BY-NC) license \\ (https://creativecommons.org/licenses/by-nc/4.0/). See http://ivyspring.com/terms for full terms and conditions.
}

Received: 2017.12.10; Accepted: 2018.05.04; Published: 2018.06.08

\begin{abstract}
Prosthetic joint infection usually requires combined medical and surgical therapy. While revision surgery is widely considered to be the gold standard surgical procedure, debridement, antibiotics and irrigation with implant retention is a very appealing alternative.

There is however great controversy regarding its real worth with success rates ranging from $0 \%$ to over $90 \%$. A number of different patient and host related variables as well as specific aspects of surgical and medical management have been described as relevant for the final outcome.

Along this paper, the authors will provide the readers with a critical narrative review of the currently available literature while trying to provide concise and practical treatment recommendations regarding adequate patient selection criteria, proper surgical technique and optimal antibiotic therapy.
\end{abstract}

Key words: Prosthetic Joint Infection; Irrigation and Debridement; Implant retention; Total Knee Arthroplasty, Total Hip Arthroplasty; Complications

\section{Introduction}

Debridement, Antibiotics and Irrigation with implant Retention (DAIR) is an appealing treatment alternative for prosthetic joint infections (PJI). It is less demanding than revision surgery both for the surgeon and the patient. It is less time consuming and technically easier to perform than revision surgery and it represents a reduced physiologic insult making it easier to recover from.

It has been shown that successful DAIR procedures lead to equivalent outcomes to uninfected controls with regards to function and quality of life[1, 2]. However, patients who have undergone DAIR and failed, often undergo multiple subsequent surgical procedures adding morbidity and cost to the process. Moreover, some studies show poor results of two-stage exchange after failed initial DAIR treatment thus recommending caution in its use [3, 4].

It is not possible to discuss the nuances surrounding DAIR for PJI treatment without a prior acknowledgment of the microbial biofilm paradigm. Ever since the original work by Gristina \& Costerton[5], a considerable amount of research has supported this concept[6]. Biofilms are highly structured usually adherent communities of microbial cells (of one or several different species) that express different phenotypes than its planktonic counterparts. They further produce extracellular matrices that surround them allowing for cell-to-cell communication and creating a favorable environment that protects the bacteria against the host immune system 
and most antibiotics although the exact mechanisms of such resistance are not fully understood $[7,8]$.

Currently, there is extensive controversy in the literature regarding the real worth of DAIR procedures with success rates ranging from $0 \%$ to over $90 \%$, and averaging at around 50\%[9-11]. There are a lot of variables possibly contributing to this wide range of reported success rate. The goal of this review is to make a critical appraisal of currently available knowledge with a special emphasis on conceivable selection criteria and practical treatment recommendations.

\section{Indications and Risk Factors for Failure}

Despite the wide variability of recommendations present in the literature, it is indisputable that such an attempt should only be made with a curative intent when facing a well-fixed, well positioned and stable prosthesis (i.e. one worth saving) and when there is a good soft tissue envelope to cover the prosthesis.

Several variables have been implicated in the likelihood of success of this procedure. Some of them such as the actual technique of the procedure and the antibiotic regimen are under the direct control of the medical team, others such as time since presentation, host medical status or even the causative pathogen are not, but may serve as selection criteria to find the best indication for treatment with implant retention.

\section{Duration of Symptoms}

Duration of symptoms is a major factor implicated in the prognosis of DAIR. It is important to emphasize the difference between duration of symptoms (i.e. time since infection manifests itself and treatment) and the "joint age" (or time from implant/index surgery to presentation). In fact, successful outcomes are possible in acute postoperative but also late acute hematogenous infections although some papers seem to point to a less favorable scenario in the latter [12-15]. In other words, it would seem duration of infection and not "joint age" is the decisive factor. The problem in clinical practice is how to be sure that a hematogenous infection is really an acute infection and not an exacerbation of a chronic infection. In fact, not all patients report long lasting symptoms prior to their presentation with a chronic infection and this may be the explanation for less favorable outcomes sometimes found in late acute hematogenous PJI.

Despite the large amount of evidence describing the importance of short duration of symptoms, there are many discrepancies concerning the best threshold for optimal outcomes (see Table 1). Still, the three and four weeks limit for hematogenous and postoperative infections respectively that was proposed by Zimmerli et al.[16] in their original treatment algorithm is widely adopted and finds support in the current literature [17-24].

An international consensus meeting (ICM) suggested DAIR could be performed in early postoperative infections that occur within 3 months of index primary arthroplasty or in late hematogenous infection that occur within 3 weeks of an inciting event with less than 3 weeks of symptoms in either case[25]. Although such a time-frame is controversial, there is some evidence suggesting it's merit. Although Grammatopoulos et al. [14] did find significantly greater chances to eradicate PJI if DAIR was undertaken within 6 weeks from the index procedure, good PJI eradication was seen even if DAIR was undertaken after $6(78 \%)$ or even 13 weeks $(83 \%)$.

Table 1. Summary of selected findings that increase risk of failure after DAIR

\begin{tabular}{|c|c|c|c|c|c|c|}
\hline & \multicolumn{3}{|c|}{ Study details } & \multicolumn{3}{|l|}{ Factors increasing failure } \\
\hline & Joint(s) & Country of Origin & Success Rate & Duration of Symptoms & Microorganism(s) & Host Status \\
\hline Byren et al.[18] 2009 & $\begin{array}{l}52 \mathrm{THA}+51 \\
\text { TKA }+9 \\
\text { other joints }\end{array}$ & UK & $81 \%$ & $\begin{array}{l}>14 \text { days from } \\
\text { presentation to } \\
\text { debridement }\end{array}$ & S. aureus PJI & Presence of co-morbidity \\
\hline Azzam et al.[12] 2010 & $\begin{array}{l}53 \mathrm{THA}+53 \\
\text { TKA }\end{array}$ & USA & $44 \%$ & $\begin{array}{l}\text { Duration of symptoms } \\
\text { failed to predict outcome }\end{array}$ & $\begin{array}{l}\text { Staphylococci PJI; frank } \\
\text { purulence }\end{array}$ & ASA score III/IV \\
\hline Peel et al.[34] 2012 & $\begin{array}{l}118 \text { THA + } \\
29 \text { TKA }\end{array}$ & Australia & $71 \%$ & $\begin{array}{l}\text { Only included PJI within } \\
90 \text { days of implantation }\end{array}$ & Gram negative PJI & $\begin{array}{l}\text { Previous septic exchange; hypotension at } \\
\text { presentation; }\end{array}$ \\
\hline Buller et al.[17] 2012 & $\begin{array}{l}62 \text { THA }+ \\
247 \text { TKA }\end{array}$ & USA & $52 \%$ & $\begin{array}{l}>21 \text { days duration of } \\
\text { symptoms }\end{array}$ & $\begin{array}{l}\text { Staphylococci PJI; VR } \\
\text { Enterococci }\end{array}$ & $\begin{array}{l}\text { Previous joint infection; higher ESR at } \\
\text { presentation; }\end{array}$ \\
\hline Kuiper et al.[21] 2013 & $\begin{array}{l}62 \text { THA }+29 \\
\text { TKA }\end{array}$ & Netherlands & $66 \%$ & $\begin{array}{l}>7 \text { days before the start } \\
\text { of treatment }\end{array}$ & CoN Staphylococci PJI & $\begin{array}{l}\text { Rheumatoid Arthritis; ESR }>60 \mathrm{~mm} / \mathrm{h} \text { at } \\
\text { presentation }\end{array}$ \\
\hline Fehring et al.[20] 2013 & $\begin{array}{l}40 \text { THA }+46 \\
\text { TKA }\end{array}$ & USA & $47 \%$ & $\begin{array}{l}31-90 \text { days worse than } \\
<30 \text { days (joint age) }\end{array}$ & $\begin{array}{l}\text { Type of microorganism } \\
\text { failed to predict outcome }\end{array}$ & $\begin{array}{l}\text { Charlson Comorbidity Index failed to } \\
\text { predict outcome }\end{array}$ \\
\hline Tornero et al.[22] 2015 & $\begin{array}{l}85 \mathrm{THA}+ \\
137 \mathrm{TKA}\end{array}$ & Spain & $77 \%$ & $\begin{array}{l}\text { Only included PJI with } \\
\text { duration of symptoms } \\
<21 \text { days }\end{array}$ & $\begin{array}{l}\text { All cultures positive } \\
\text { during debridement }\end{array}$ & $\begin{array}{l}\text { Chronic renal failure; liver cirrhosis; } \\
\text { revision surgery or cemented prosthesis; } \\
\text { CRP }>11.5 \mathrm{mg} / \mathrm{dL} \text {; (KLIC score) }\end{array}$ \\
\hline $\begin{array}{l}\text { Grammatopoulos et } \\
\text { al.[14] } 2017\end{array}$ & 122 THA & UK & $85 \%$ & $\begin{array}{l}>6 \text { weeks after index } \\
\text { procedure }\end{array}$ & $\begin{array}{l}\text { Type of microorganism } \\
\text { failed to predict outcome }\end{array}$ & Higher KLIC score \\
\hline
\end{tabular}


Although time does matter for biofilm formation, DAIR should not be viewed as an emergency procedure except in patients with overt generalized sepsis. Efforts should be made to optimize the patient's comorbidities and whenever possible the procedure should be performed by an experienced septic surgeon.

\section{Type of Microorganism}

Although it is of great consequence, specific information about the infecting microorganism(s) and its antibiotic susceptibility is frequently not fully known when choosing to perform surgery.

Indeed, staphylococci infections have been frequently implicated in unfavorable results after DAIR[12, 17, 18, 26, 27]. Methicillin-resistant $S$. aureus (MRSA) specifically, are traditionally considered to be a major risk for failure of debridement with component retention even in acute infections[28-30].

Bradbury et al.[30] have even proposed that if MRSA is encountered, subsequent treatment with exchange arthroplasty should be considered. Joulie et al.[31] analyzed which variables were associated with treatment failure in 93 PJI caused by $S$. aureus. Although they found that exchange arthroplasty offered a better probability of success than debridement alone, they did not find the healing rate to be influenced by methicillin resistance[31]. In a more recent large retrospective, multicenter, observational study of cases of $S$. aureus PJI that were managed with DAIR, the authors found no difference in failure rates in MRSA compared to methicillin sensitive cases[32]. Nevertheless, both these papers showed DAIR was able to save only about $55-57 \%$ of $S$. aureus infections $[31,32]$.

Gram negative microorganisms are also a classic concern as they have traditionally been implicated in worse outcomes with implant retention surgery[33, 34]. Nevertheless, it seems that if fundamental principles such as short duration of symptoms and anti-biofilm antibiotic therapy are upheld, success of DAIR procedure can be just as good in this group of patients[35-38]. The key problem in managing Gram negative PJI is the growing antibiotic resistance pattern, especially in the Middle East and Asia as well as in the European Mediterranean region[39, 40]. It has been shown that the prognosis after DAIR is dramatically decreased when fluoroquinolone resistance is found[36]. Furthermore, even more serious problems such as combined resistance to third-generation cephalosporins, fluoroquinolones and aminoglycosides are often encountered, greatly reducing antibiotic treatment alternatives[39]. Carbapenemase-producing Enterobacteriaceae are also on the horizon and have already been implicated in
PJI with dire consequences[41].

Enterococcus sp. Infections, although uncommon, are also of special concern as they are implicated in poor outcomes with overall success rates of around $50 \%$ [42-44]. This is particularly true when enterococci infection occurs in a polymicrobial setting or exhibits vancomycin resistance[17, 42]. A major European multicenter study including data from 18 hospitals of six different countries focused exclusively on PJI due to Enterococcus sp.[44]. They found an overall success rate of 56\% (100/178) among patients with at least one year follow-up after surgery. Implant removal showed a higher remission rate than DAIR but this reached statistical significance only in those patients with more than two years from arthroplasty to infection[44]. A recent American multicenter study confirms these findings as their overall success rate was also low at $52 \%(45 / 87)$ [42]. In this study, success rate after DAIR was only 39\% (13/33) which was significantly lower than results after two-stage exchange. Despite that finding, it has been shown that a standardized DAIR protocol for treatment of early infections can lead to slightly superior results. Duijf et al.[45] reported on 44 patients with early Enterococci infections (35 polymicrobial). Debridement was performed at an average of 15 days after the index implantation and patients were treated with teicoplanin, rifampicin, vancomycin or amoxicillin or a combination of these antibiotics for three months postoperatively. The prosthesis could successfully be retained in 29 patients $(66 \%)$ which is, nevertheless, worse than with other microorganisms[45].

Streptococcal infections on the other hand have classically shown a more favorable prognosis[14, 26, 46]. Still, a recent retrospective, observational, multicenter, international study that presents the largest series of streptococcal PJI managed by DAIR with 462 cases, showed a worse prognosis than previously reported[47]. However, given the nature of the study design and according to the authors own admission the criteria for ideal case selection were not strictly met by many patients, and the decision to undergo DAIR was taken by individual medical group on a case by case basis[47].

Depending on the specific microorganisms involved, polymicrobial infections potentially accumulate many of the limitations aforementioned and it is natural that they are often implicated in limited success rates after DAIR[48, 49].

\section{Technical Aspects of the Procedure (including Mobile Parts Exchange)}

The main goal of surgical debridement is to lower the bacterial load within the joint as much as possible. In that regard, debridement must be 
thorough and meticulous and all devitalized tissues must be excised. This is a major variable that is not possible to accurately assess when reviewing the results in the literature.

Despite the wide range of suggestions regarding the best way to perform a DAIR procedure, common ground has been reached as to what constitutes a favorable debridement[25]. After preoperative optimization of the patient has been achieved, good visualization and thorough debridement should be performed, multiple culture samples should be obtained before copious irrigation (6 to $9 \mathrm{~L}$ ) of the joint. Even when choosing to perform a DAIR, patients should be advised that the prosthesis may still need to be explanted if indicated (e.g. if it is found to be loose).

Mobile parts exchange seems to be an important factor for success. Naturally, removing mobile parts and replacing them by new ones removes associated bacterial biofilm, allows access to parts of the joint that are otherwise inaccessible and it allows for removal of slime from the undersurface of such components, leading to better reduction of bacterial load. Polyethylene exchange is widely recommended and there seems to be enough evidence of its beneficial impact on outcome[13, 16, 17, 19, 21, 23, 25, $36,50-61]$. In a massive retrospective study including over 16,600 PJI, the authors tried to determine risk factors for reinfection after treatment of infected TKA in the United States[52]. They found that patients who underwent DAIR as a first-line treatment had the highest risk of reinfection, compared to one- and two-stage revision surgery or amputation[52]. More interestingly, they found that DAIR with liner exchange had significantly reduced risk of reinfection even after adjusting for all other available variables[52]. Considering all of the above premises, it is natural to assume that arthroscopic debridement will not suffice. Indeed, even when a posterior portal is routinely used to enable debridement of the posterior compartment of the knee, this approach is not as effective as an open debridement $[18,62,63]$.

\section{Adjuvant(s) of Debridement}

Although they should not be considered surrogates for adequate surgical debridement, some adjuvant therapies have been advocated as useful during the procedure. By far the most commonly used is to irrigate the joint with copious amounts of normal saline. Although there is the concern that high-pressure pulsatile lavage systems may cause iatrogenic bacterial seeding into deeper tissue layers[64], both low-pressure or high-pressure lavage can be used and no significant difference as been shown to exist in clinical practice[65]. Some authors argue that adding some kind of chemical to the irrigation liquid could help in reducing bacterial load.

In that regard, detergents, antiseptics or even antibiotics have been proposed but there is very limited evidence of its efficacy in clinical practice and most findings originate from in vitro studies. Simply adding antibiotics to the lavage fluid, as appealing as it may appear, has been shown to be no better than saline alone[66, 67]. In light of our current knowledge about the pathogenesis of PJI, it is natural to expect that some kind of "anti-biofilm" agent would perform better. In fact, there is evidence that detergents such as castile soap or benzalkonium chloride are more effective in disrupting biofilm from metal surfaces than saline alone[66, 68]. More recently, chlorhexidine gluconate scrub (antiseptic and detergent) was shown to be the most effective option at decreasing bacterial colony counts when compared to normal saline, povidone iodine scrub or castile soap[69, 70]. An interesting alternative may be acetic acid, commonly known as vinegar. It has been shown in vitro to be highly effective against both Gram positive and Gram negative biofilms[71]. There is also limited clinical evidence of the efficacy and safety profile of a 20 minutes' soak of $3 \%$ acetic acid solution in the debridement of infected TKA[72].

A different approach is to try and complement surgical debridement by delivering local antibiotics in extremely high concentrations that are able to help eradicate biofilm remnants. Two different ways of achieving this goal have been pursued although there is insufficient evidence to definitively support the use of either until now. Direct continuous intra-articular delivery of antibiotics into the joint was initially promoted by Whiteside as an additional treatment in exchange revision surgery both for knee and hips[73-75]. Fukugawa et al.[58] were the first to apply this concept after DAIR. They reported on a small series of six infected primary TKA, one revision TKA and five tumor mega-prosthesis. There were four recurrences, all of them occurring in the mega-prosthesis group[58]. There are some potential concerns associated with this practice, including drug reactions or possible re-infection through the catheters used to infuse the antibiotic and the need for an additional surgery (to remove the Hickman catheter necessary for the intra-articular infusion) and the available evidence is not enough to state that intra-articular delivery of antibiotics into the joint is an independent success factor.

Another way to deliver local antibiotics that has been explored, is to use some kind of antibiotic-impregnated carrier (PMMA beads, calcium sulphate pellets, collagen fleece, etc.). Antibiotic impregnated PMMA beads have a long tradition in 
bone septic surgery and there are some papers exploring its use after DAIR in total joint infections[19, 21, 59, 76]. They do however force a second surgery for its removal and this has moved the focus on to resorbable material such as collagen fleece or calcium sulphate pellets[21,59,76]. Although small series have shown encouraging results, there are no randomized, controlled studies to clearly demonstrate that the use of these materials enhances the outcome of a properly performed procedure. Furthermore, resorbable antibiotic carriers are not without problems such as increased cost, local reactions and increased/persistent wound drainage.

\section{Antibiotic Treatment}

Following adequate debridement, correct antibiotic therapy is critical in achieving infection eradication. Most of the times, DAIR procedures will take place without previous knowledge of the responsible pathogen and effective empiric antibiotic therapy must be initiated while waiting for intraoperative culture results.

\section{Initial therapy}

In the early phase of acute PJI, planktonic bacteria predominate and so treatment usually starts with intravenous (IV) therapy. After the initial debulking of bacterial load caused by surgery and IV antibiotics the switch to regimens with high oral bioavailability and anti-biofilm activity can be made thus avoiding prolonged hospital stay and related complications. Traditionally, 2- 6 weeks of intravenous antimicrobial therapy has been recommended[24] but there is growing evidence that shortening IV therapy before switching to oral therapy is probably not detrimental[77].

Exact empirical antibiotic regimens must be nation or institution specific in accordance with local microbial flora antibiotic susceptibility patterns. As soon as definitive microbiology results are available, antibiotic therapy is deescalated according to isolated pathogen(s) and antibiotic susceptibility pattern.

\section{Continuation therapy}

The heterogeneous nature of PJI concerning both the microorganisms and the host, results in a huge diversity of clinical scenarios that make it impossible to offer universal solutions. Every case must be considered on an individual basis and multidisciplinary consultation including infectious diseases specialists is critical. There are however some helpful guidelines available for consultation[16, 24].

Notwithstanding, antibiotic therapy after DAIR procedures holds some peculiarities that must be observed. Unlike revision surgery where the implant is removed, it is natural to expect the presence of biofilm remnants in the prosthesis after surgical debridement. As such, selected antibiotics should ideally have anti-biofilm activity. In this regard, ever since the pioneer work by Zimmerli[78] et al., rifampicin has gained an indisputable role in biofilm-related staphylococci infections[13, 16, 51, 60, $61,77,79-81]$. Interestingly, it has also been suggested that rifampicin in combination with other antibiotics may also lead to lower rate of failure in early Enterococcus sp. infections treated with DAIR[44]. It is important to stress that, because bacteria rapidly develop antimicrobial resistance, rifampicin should never be administered alone but rather in combination therapy[16]. Plus, it should only be used after the bulk of bacterial load has been eliminated and never in persistently draining wounds[82]. Acherman et al.[82] have found that rifampicin therapy with inadequate surgical debridement or less than two weeks of intravenous treatment was independently associated with emergence of rifampicin resistance.

An analogous declaration of importance can be made regarding the use of quinolones in Gram negative (GN) infections. There is good evidence to recommend the use of quinolones when facing adequately sensitive GN microorganisms[35, 36, 77, 83]. In a recent large multicenter study including 242 Gram negative PJI, ciprofloxacin therapy exhibited an independent protective effect[36]. In patients with ciprofloxacin-susceptible GN-PJI treated with ciprofloxacin, success was $79 \% \quad(98 / 124)$. In ciprofloxacin-resistant cases, the efficacy of DAIR management was at $41 \%(14 / 34)$. In those with susceptible isolates not treated with ciprofloxacin success rate was similar at $40 \%(6 / 15)$, suggesting lack of ciprofloxacin use and not resistance pattern is responsible for the negative impact. The effectiveness of ciprofloxacin in these patients is probably attributable to its acceptable oral bioavailability, optimal diffusion into synovial fluid and bone, and activity against biofilm[84].

Correct antibiotic regimen is a critical part of therapy. A very recent paper by Tornero et al.[77] confirms that incorrect antibiotic selection is the most important predictor of late failure after DAIR. In their study of 143 patients, antibiotic treatment was categorized as optimal if it included a combination of rifampicin plus rifampicin-independent antibiotic (levofloxacin, ciprofloxacin or amoxicillin) or monotherapy without rifampicin for Gram positives and when it included a fluoroquinolone for Gram negatives. It was found to be suboptimal if it included a combination of rifampicin plus rifampicindependent antibiotic (linezolid, co-trimoxazole or 
clindamycin) for Gram positive or a regimen without fluoroquinolone for Gram negative. Receiving suboptimal antibiotic treatment proved to be the only independent predictor of failure in this study[77].

\section{Duration of therapy}

The duration of antibiotic treatment after DAIR is also matter of intense controversy. Traditionally, guidelines have recommended 3 months for infections in total hip and 6 months for total knee prosthesis[24]. There are however several papers questioning this axiom.

Tornero et al.[77] found no relationship between failure and duration of treatment after a median duration of intravenous and oral antibiotic treatment of 8 days and 69 days respectively. A similar finding was reported by Lora-Tamayo[85] et al. in a randomized clinical trial including over 60 patients with acute staphylococcal PJI managed with DAIR. Patients were randomized to receive 8 weeks of treatment (short schedule) versus a long schedule (3 months or 6 months for hip or knee prostheses, respectively) of levofloxacin plus rifampicin. They suggest that the short schedule could be just as effective as a longer standard treatment for THA but some doubt persisted over its value for TKA[85]. Despite some conflicting evidence, extending therapy for 3 months seems to be sufficient for the majority of cases[60, 61, 77, 81, 83]. Although many physicians rely on C-reactive protein serial measurements to guide antibiotic discontinuation, this practice has been found to be unreliable and not predictive of failure and should therefore be discouraged [85-87].

\section{Failure and treatment options}

In an effort to accurately predict the probability of success thus helping decide on the best course of treatment, some authors have tried to come out with prognostic preoperative scores such as the KLIC-score [22]. This score based on patient and index surgery specific variables has been shown to be highly predictive especially in the lower and upper ends of the spectrum $[14,22,88,89]$. While, data on prospectively applying these tools for decision-making before DAIR is undertaken is still missing, it seems natural to rely on it for reconsideration after initial treatment failure.

Failures can be broadly divided into early failures where DAIR fails to achieve infection control and late failures where infection relapses after apparent good initial response. In both cases, recurrent PJI after DAIR procedures is most often due to identical microorganisms suggesting treatment failed to eradicate infection effectively $[12,17,18,21$, $22,27]$.

Table 2. Summary of selected recent findings regarding antibiotic regimen after DAIR

\begin{tabular}{|c|c|c|c|c|}
\hline & Joint(s) & $\begin{array}{l}\text { Country of } \\
\text { Origin }\end{array}$ & $\begin{array}{l}\text { Overall Success } \\
\text { Rate }\end{array}$ & Major finding(s) \\
\hline Aboltins et al.[35] 2011 & 15 THA + 2 TKA & Australia & $\begin{array}{l}94 \% \\
\text { at the 2-years } \\
\text { follow-up }\end{array}$ & $\begin{array}{l}\text { Exclusively GN PJI - oral ciprofloxacin in } 14 \text { cases and amoxicillin/clavulanic acid in three } \\
\text { cases } \\
\text { Median duration of oral antibiotic treatment was } 12 \text { months }\end{array}$ \\
\hline Vilchezet al.[81] 2011 & $18 \mathrm{THA}+35$ TKA & Spain & $\begin{array}{l}75 \% \\
\text { minimum } \\
\text { two-year } \\
\text { follow-up }\end{array}$ & $\begin{array}{l}\text { Exclusively S. aureus PJI - rifampin combination therapy in } 91 \% \text { of the patients. Only } 4 \\
\text { MRSA. } \\
\text { Duration of antibiotic therapy }>90 \text { days did not improve outcome }\end{array}$ \\
\hline Puhto et al.[61] 2012 & $55 \mathrm{THA}+77 \mathrm{TKA}$ & Finland & $\begin{array}{l}65 \% \\
\text { at the 2-years } \\
\text { follow-up }\end{array}$ & $\begin{array}{l}\text { Rifampin combination(s) preferred for staphylococci and quinolones preferred for GN } \\
\text { Reducing duration of treatment to } 3 \text { months (vs. 6) for TKA and } 2 \text { months (vs. 3) for THA did } \\
\text { not influence outcome }\end{array}$ \\
\hline Peel et al.[60] 2013 & $28 \mathrm{THA}+15 \mathrm{TKA}$ & Australia & $\begin{array}{l}77 \% \\
\text { at the 2-years } \\
\text { follow-up }\end{array}$ & $\begin{array}{l}\text { Exclusively MR staphylococci PJI - rifampin combination therapy in } 93 \% \text { of the patients } \\
\text { MRSA infections and <90 days antibiotic therapy were more likely to fail }\end{array}$ \\
\hline $\begin{array}{l}\text { Rodríguez-Pardo et } \\
\text { al.[36] } 2014\end{array}$ & $\begin{array}{l}115 \text { THA }+57 \text { TKA } \\
+2 \text { other joints }\end{array}$ & Spain & $\begin{array}{l}68 \% \\
\text { median } 25 \text {-months } \\
\text { follow-up }\end{array}$ & $\begin{array}{l}\text { Exclusively GN PJI - } 79 \%(98 / 124) \text { success rate in ciprofloxacin-susceptible treated with it } \\
41 \%(14 / 34) \text { success rate in ciprofloxacin-resistant and } 40 \%(6 / 15) \text { success rate in } \\
\text { ciprofloxacin-susceptible not treated with it } \\
79 \%(33 / 42) \text { success rate in Pseudomonas PJI increased to } 88 \%(29 / 33) \text { when treated with } \\
\text { ciprofloxacin } \\
53 \%(8 / 15) \text { success rate in ESBL-producing Enterobacteriaceae PJI } \\
\text { Median antibiotic treatment duration was } 70 \text { days }\end{array}$ \\
\hline $\begin{array}{l}\text { Holmberg et al.[13] } \\
2015\end{array}$ & 145 TKA & Sweden & $\begin{array}{l}75 \% \\
\text { minimum } \\
\text { one-year } \\
\text { follow-up }\end{array}$ & $\begin{array}{l}\text { Risk of failure was } 4 \text { times higher if no rifampin used in staphylococci infections (59\% vs } 19 \% \text { ) } \\
\text { Failure rate was higher in polymicrobial ( } 9 / 30) \text { and Gram negative cases (2/5) - albeit not } \\
\text { statistically significant } \\
\text { Large variation in duration of antibiotic treatment }\end{array}$ \\
\hline $\begin{array}{l}\text { Lora-Tamayo et } \\
\text { al.[85]2016 }\end{array}$ & 29 THA + 24 TKA & Spain & $\begin{array}{l}93 \% \\
\text { minimum } \\
\text { one-year } \\
\text { follow-up }\end{array}$ & $\begin{array}{l}\text { Randomized and open trial. Exclusively staphylococci acutePJI receiving } \\
\text { rifampin-levofloxacin combination. } \\
\text { Cure rate in the patients who completed antibiotic treatment was } 22 / 24(92 \%) \text { in the short ( } 8 \\
\text { weeks) protocol vs. } 19 / 20(95 \%) \text { in the long ( } 3 \text { and } 6 \text { months for THA and TKA respectively) }\end{array}$ \\
\hline Grossi et al.[83] 2016 & $\begin{array}{l}35 \text { THA + } 18 \text { TKA } \\
+23 \text { Hemi hips }\end{array}$ & France & $\begin{array}{l}79 \% \\
\text { minimum } \\
\text { one-year } \\
\text { follow-up }\end{array}$ & $\begin{array}{l}\text { Exclusively GN PJI: } 35 \text { DAIR procedures }-8(22 \%) \text { failed } \\
\text { Failure rate was similar whether fluoroquinolones or three month IV B-lactams were used } \\
\text { Median antibiotic treatment duration was } 90 \text { days }\end{array}$ \\
\hline
\end{tabular}

DAIR -Debridement Antibiotics and Irrigation with implant Retention; TKA -Total knee arthroplasty; THA -Total hip arthroplasty; MRSA -methicillin-resistant S. aureus; GN -Gram negative 
In the first clinical scenario, a repeated surgical debridement may be attempted although this strategy is highly controversial. On one hand, Vilchez et al.[81] found the need for a second debridement to be associated with failure. These results were confirmed in a large, retrospective multicenter study of $S$. aureus PJI $(n=345)$ where the need of a second debridement was an independent variable associated with failure[32]. On the other hand, there are a number of papers that do not find the need for more than one unplanned debridement to be associated with worse outcomes[18, 21, 59]. This controversy is even more intricate by the fact that some centers advocate for standard repeated debridements every $48-72 \mathrm{~h}$ in order to reduce the bacterial load regardless of clinical evolution. Peel et al.[60] performed protocoled multiple debridements and found the optimal number to be two or three as there was significantly higher risk of failure in patients with either a single or at least four surgical debridements.

Recently, Moojen et al.[90] compared these two different strategies in the treatment of acute THA infection. Although it was not statistically significant, they did find an increased failure rate in the group of patients that always received multiple surgical debridements (10/35) as compared to the group of patients that received a single surgical debridement and only additional surgery if infectious symptoms persisted (4/33)[90]. Additionally, in the former group, new and more resistant microorganisms were found in subsequent debridements suggesting every time the wound is opened there is a risk of further contamination[90].

Another treatment alternative is to proceed to implant removal. Although the real impact of previous failed DAIR on the likelihood of success after exchange surgery is not yet fully understood, most surgeons would agree that exchange surgery is the natural choice when facing a late infection relapse[3, 4, 91]. The same might be true in some cases of early failure, especially if significant risk factors for DAIR failure are present (e.g. high KLIC score, unfavorable microbial pathogen, etc.) as previously discussed.

\section{Future Perspectives}

Presently, duration of infection before DAIR is indisputably a major variable to consider as it correlates directly to the microbial biofilm paradigm. It is known that the development of a biofilm onto an orthopedic implant starts within the first few minutes and hours after exposure. There is a progressive maturation process and younger biofilms do seem to be more susceptible to (a limited number of) antibiotics than more mature biofilms and this is a major premise behind adequate case selection for DAIR[8]. What constitutes the difference and where the exact frontier is between a young susceptible biofilm and a more mature resistant infection is still undetermined. Naturally some way to differentiate chronic mature biofilm infections from acute cases where biofilm is still susceptible would be of great benefit. A promising research path based on serological detection of elevated levels of antibody to microbial antigens, specifically "anti-biofilm" antigens is underway $[92,93]$.

Another potential target would be to increase our ability to cause biofilm disruption in vivo. Chlorhexidine and acetic acid are examples of such strategies that are already being used but they offer limited efficacy. Presently, rifampicin and ciprofloxacin to some degree are the only effective antibiotic therapy and alternative drug(s) are desperately needed. Antimicrobial peptides (ex. chitosan) are a new class of antibiotics with very interesting features. They are highly active against a broad spectrum of microorganisms, highly selective towards microorganisms and not mammalian cells, present fast killing even at low concentrations and most importantly, they have a much lower tendency to induce resistance[94]. If in vivo biofilm disruption therapy becomes real, the need for revision surgery would greatly diminish.

\section{Conclusion}

For the time being accurate case selection and attention to detail in every aspect of treatment such as rigorous surgical procedure technique and adequate postoperative anti-biofilm antibiotic therapy is critical if DAIR is to be performed.

However, in some extreme clinical conditions, usually old and frail patients, DAIR may be indicated as a means to temporarily alleviate symptoms caused by planktonic bacteria leaving the biofilm during acute exacerbations of a chronically infected implant. It will not be able to eradicate biofilm and ensuing chronic suppressive antibiotic therapy is often required but sometimes this may be the lesser of two evils in situations where the patient is not fit to undergo major revision surgery.

It is the authors belief that if appropriate minimal conditions are met (short duration of symptoms in a stable and well-fixed prosthesis with sound soft tissues and no sinus tract), DAIR should be regarded as first-line treatment choice in the vast majority of cases. This approach has resulted in successful infection eradication in $85 \%$ of cases at two-years minimum follow-up[95]. 


\section{Acknowledgements}

The authors would like to thank Dr. Robert Ford (MD) for editing the final version of the manuscript.

\section{Competing Interests}

The authors have declared that no competing interest exists.

\section{References}

1. Dzaja I, Howard J, Somerville L, Lanting B. Functional outcomes of acutely infected knee arthroplasty: a comparison of different surgical treatment options. Can J Surg. 2015; 58(6): 402-7.

2. Grammatopoulos G, Bolduc ME, Atkins BL, Kendrick BJL, McLardy-Smith P, Murray DW, et al. Functional outcome of debridement, antibiotics and implant retention in periprosthetic joint infection involving the hip: a case-control study. Bone Joint J. 2017; 99-B(5): 614-22.

3. Sherrell JC, Fehring TK, Odum S, Hansen E, Zmistowski B, Dennos A, et al. The Chitranjan Ranawat Award: fate of two-stage reimplantation after failed irrigation and debridement for periprosthetic knee infection. Clin Orthop Relat Res. 2011; 469(1): 18-25.

4. Gardner J, Gioe TJ, Tatman P. Can this prosthesis be saved?: implant salvage attempts in infected primary TKA. Clin Orthop Relat Res. 2011; 469(4): 970-6.

5. Gristina AG, Costerton JW. Bacterial adherence and the glycocalyx and their role in musculoskeletal infection. Orthop Clin North Am 1984; 15(3): 517-35

6. Tzeng A, Tzeng TH, Vasdev S, Korth K, Healey T, Parvizi J, et al. Treating periprosthetic joint infections as biofilms: key diagnosis and management strategies. Diagn Microbiol Infect Dis 2015; 81(3): 192-200.

7. Costerton JW, Stewart P, Greenberg EP. Bacterial biofilms: a common cause of persistent infections. Science 1999; 284(5418): 1318-22.

8. Gbejuade HO, Lovering AM, Webb JC. The role of microbial biofilms in prosthetic joint infections. Acta Orthop. 2015; 86(2): 147-58.

9. Romano C, Logoluso N, Drago L, Peccati A, Romano D. Role for irrigation and debridement in periprosthetic infections. J Knee Surg 2014; 27(4): 267-72.

10. Romano CL, Manzi G, Logoluso N, Romano D. Value of debridement and irrigation for the treatment of peri-prosthetic infections. A systematic review. Hip Int 2012; 22 Suppl 8: S19-24.

11. Triantafyllopoulos GK, Soranoglou V, Memtsoudis SG, Poultsides LA. Implant retention after acute and hematogenous periprosthetic hip and knee infections: Whom, when and how? World J Orthop. 2016; 7(9): 546-52.

12. Azzam KA, Seeley M, Ghanem E, Austin MS, Purtill JJ, Parvizi J. Irrigation and debridement in the management of prosthetic joint infection: traditional indications revisited. J Arthroplasty. 2010; 25(7): 1022-7.

13. Holmberg A, Thorhallsdottir VG, Robertsson O, W-Dahl A, Stefansdottir A. $75 \%$ success rate after open debridement, exchange of tibial insert, and antibiotics in knee prosthetic joint infections. Acta Orthop. 2015; 86(4): 457-62.

14. Grammatopoulos G, Kendrick B, McNally M, Athanasou NA, Atkins B, McLardy-Smith $\mathrm{P}$, et al. Outcome Following Debridement, Antibiotics, and Implant Retention in Hip Periprosthetic Joint Infection-An 18-Year Experience. J Arthroplasty. 2017; 32(7): 2248-55.

15. Rodriguez D, Pigrau C, Euba G, Cobo J, Garcia-Lechuz J, Palomino J, et al. Acute haematogenous prosthetic joint infection: prospective evaluation of medical and surgical management. Clin Microbiol Infect 2010; 16(12): 1789-95.

16. Zimmerli W, Trampuz A, Ochsner PE. Prosthetic-joint infections. N Engl J Med. 2004; 351(16): 1645-54.

17. Buller LT, Sabry FY, Easton RW, Klika AK, Barsoum W. The preoperative prediction of success following irrigation and debridement with polyethylene exchange for hip and knee prosthetic joint infections. J Arthroplasty. 2012; 27(6): 857-64.e1-4.

18. Byren I, Bejon P, Atkins BL, Angus B, Masters S, McLardy-Smith P, et al. One hundred and twelve infected arthroplasties treated with 'DAIR' (debridement, antibiotics and implant retention): antibiotic duration and outcome. J Antimicrob Chemother. 2009; 63(6): 1264-71.

19. Estes CS, Beauchamp CP, Clarke HD, Spangehl MJ. A two-stage retention debridement protocol for acute periprosthetic joint infections. Clin Orthop Relat Res. 2010; 468(8): 2029-38.
20. Fehring TK, Odum SM, Berend KR, Jiranek WA, Parvizi J, Bozic KJ, et al. Failure of irrigation and debridement for early postoperative periprosthetic infection. Clin Orthop Relat Res. 2013; 471(1): 250-7.

21. Kuiper JW, Vos SJF, Saouti R, Vergroesen DA, Graat HCA, Debets-Ossenkopp YJ, et al. Prosthetic joint-associated infections treated with DAIR (debridement, antibiotics, irrigation, and retention): analysis of risk factors and local antibiotic carriers in 91 patients. Acta Orthop. 2013; 84(4): 380-6.

22. Tornero E, Morata L, Martinez-Pastor JC, Bori G, Climent C, Garcia-Velez DM, et al. KLIC-score for predicting early failure in prosthetic joint infections treated with debridement, implant retention and antibiotics. Clin Microbiol Infect. 2015; 21(8): 786.e9-.e17.

23. Westberg M, Grogaard B, Snorrason F. Early prosthetic joint infections treated with debridement and implant retention: 38 primary hip arthroplasties prospectively recorded and followed for median 4 years. Acta Orthop. 2012; 83(3): 227-32.

24. Osmon DR, Berbari EF, Berendt AR, Lew D, Zimmerli W, Steckelberg $\mathrm{JM}$, et al. Diagnosis and management of prosthetic joint infection: clinical practice guidelines by the Infectious Diseases Society of America. Clin Infect Dis. 2013; 56(1): e1-e25.

25. Gehrke T, Parvizi J. Proceedings of the International Consensus Meeting on Periprosthetic Joint Infection. https://www.efort.org/wpcontent/ uploads/2013/10/Philadelphia_Consensus.pdf; 2013.

26. Betz M, Abrassart S, Vaudaux P, Gjika E, Schindler M, Billieres J, et al. Increased risk of joint failure in hip prostheses infected with Staphylococcus aureus treated with debridement, antibiotics and implant retention compared to Streptococcus. Int Orthop. 2015; 39(3): 397-401.

27. Zmistowski BM, Manrique J, Patel R, Chen AF. Recurrent Periprosthetic Joint Infection After Irrigation and Debridement With Component Retention Is Most Often Due to Identical Organisms. J Arthroplasty. 2016; 31(9 Suppl): 148-51.

28. Salgado CD, Dash S, Cantey JR, Marculescu CE. Higher risk of failure of methicillin-resistant Staphylococcus aureus prosthetic joint infections. Clin Orthop Relat Res 2007; 461: 48-53.

29. Siddiqui MM, Lo NN, Ab Rahman S, Chin PL, Chia Sl, Yeo SI. Two-year outcome of early deep MRSA infections after primary total knee arthroplasty: a joint registry review. J Arthroplasty. 2013; 28(1): 44-8.

30. Bradbury T, Fehring TKF, Taunton M, Hanssen A, Azzam K, Parvizi J, et al. The fate of acute methicillin-resistant Staphylococcus aureus periprosthetic knee infections treated by open debridement and retention of components. J Arthroplasty. 2009; 24(6 Suppl): 101-4.

31. Joulie D, Girard J, Mares O, Beltrand E, Legout L, Dezeque H, et al. Factors governing the healing of Staphylococcus aureus infections following hip and knee prosthesis implantation: a retrospective study of 95 patients. Orthop Traumatol Surg Res. 2011; 97(7): 685-92.

32. Lora-Tamayo J, Murillo OF, Iribarren JA, Soriano A, Sanchez-Somolinos M, Baraia-Etxaburu JM, et al. A large multicenter study of methicillin-susceptible and methicillin-resistant Staphylococcus aureus prosthetic joint infections managed with implant retention. Clin Infect Dis. 2013; 56(2): 182-9.

33. Hsieh PH, Lee MS, Hsu K-Y, Chang Y-H, Shih H-N, Ueng SW. Gram-negative prosthetic joint infections: risk factors and outcome of treatment. Clin Infect Dis. 2009; 49(7): 1036-43.

34. Peel TN, Cheng AC, Choong PFM, Buising KL. Early onset prosthetic hip and knee joint infection: treatment and outcomes in Victoria, Australia. J Hosp Infect. 2012; 82(4): 248-53.

35. Aboltins CA, Dowsey MM, Buising KL, Peel TN, Daffy JR, Choong PFM, et al. Gram-negative prosthetic joint infection treated with debridement, prosthesis retention and antibiotic regimens including a fluoroquinolone. Clin Microbiol Infect. 2011; 17(6): 862-7.

36. Rodriguez-Pardo D, Pigrau C, Lora-Tamayo I, Soriano A, del Toro MD, Cobo J, et al. Gram-negative prosthetic joint infection: outcome of a debridement, antibiotics and implant retention approach. A large multicentre study. Clin Microbiol Infect. 2014; 20(11): 911-9.

37. Veltman ES, Vos FJ, Meis JF, Goosen JH. Debridement, antibiotics and implant retention in early postoperative infection with Pseudomonas aeruginosa. J Infect 2015; 70(3): 307-9.

38. Zmistowski B, Fedorka CJ, Sheehan E, Deirmengian G, Austin MS, Parvizi J. Prosthetic joint infection caused by gram-negative organisms. J Arthroplasty 2011; 26(6 Suppl): 104-8

39. Ricciardi W, Giubbini G Laurenti P Surveillance and Control of Antibiotic Resistance in the Mediterranean Region. Mediterr J Hematol Infect Dis. 2016; 8(1).

40. Livermore DM. Current Epidemiology and Growing Resistance of Gram- Negative Pathogens. Korean J Intern Med. 2012; 27(2): 128-42.

41. de Sanctis I, Teixeira L, van Duin D, Odio C, Hall G, Tomford JW, et al. Complex prosthetic joint infections due to carbapenemase-producing 
Klebsiella pneumoniae: a unique challenge in the era of untreatable infections. Int J Infect Dis. 2014; 25: 73-8.

42. Kheir MM, Tan TL, Higuera C, George J, Della Valle CJ, Shen M, et al. Periprosthetic Joint Infections Caused by Enterococci Have Poor Outcomes. J Arthroplasty 2016; Sep 28. [Epub ahead of print]: doi: 10.1016/j.arth.2016.09.017.

43. Rasouli MR, Tripathi MS, Kenyon R, Wetters N, Della Valle CJ, Parvizi J. Low rate of infection control in enterococcal periprosthetic joint infections. Clin Orthop Relat Res. 2012; 470(10): 2708-16.

44. Tornero E, Senneville E, Euba G, Petersdorf S, Rodriguez-Pardo D, Lakatos B, et al. Characteristics of prosthetic joint infections due to Enterococcus sp. and predictors of failure: a multi-national study. Clin Microbiol Infect. 2014; 20(11): 1219-24.

45. Duijf SV, Vos FJ, Meis JF, Goosen JH. Debridement, antibiotics and implant retention in early postoperative infection with Enterococcus sp. Clin Microbiol Infect. 2015; 21(5): e41-2.

46. Odum SM, Fehring TK, Lombardi AV, Zmistowski BM, Brown NM, Luna JT, et al. Irrigation and debridement for periprosthetic infections: does the organism matter? J Arthroplasty. 2011; 26(6 Suppl): 114-8.

47. Lora-Tamayo J, Senneville E, Ribera A, Bernard L, Dupon M, Zeller V, et al. The Not-So-Good Prognosis of Streptococcal Periprosthetic Joint Infection Managed by Implant Retention: The Results of a Large Multicenter Study. Clin Infect Dis 2017; 64(12): 1742-52.

48. Marculescu CE, Cantey JR. Polymicrobial prosthetic joint infections: risk factors and outcome. Clin Orthop Relat Res. 2008; 466(6): 397-404.

49. Tornero E, Garcia-Oltra E, Garcia-Ramiro S, Martinez-Pastor JC, Bosch J, Climent $\mathrm{C}$, et al. Prosthetic joint infections due to Staphylococcus aureus and coagulase-negative staphylococci. Int J Artif Organs 2012; 35(10): 884-92.

50. Aboltins C, Dowsey MM, Peel T, Lim WK, Parikh S, Stanley P, et al. Early prosthetic hip joint infection treated with debridement, prosthesis retention and biofilm-active antibiotics: functional outcomes, quality of life and complications. Intern Med J. 2013; 43(7): 810-5.

51. Choong PF, Dowsey MM, Carr D, Daffy J, Stanley P. Risk factors associated with acute hip prosthetic joint infections and outcome of treatment with a rifampinbased regimen. Acta Orthop. 2007; 78(6): 755-65.

52. Cochran AR, Ong KL, Lau E, Mont MA, Malkani AL. Risk of Reinfection After Treatment of Infected Total Knee Arthroplasty. J Arthroplasty. 2016; 31(9 Suppl): 156-61.

53. Kim JH, Chun SK, Yoon YC, Lakhotia D, Shon WY. Efficacy of Debridement for Early Periprosthetic Joint Infection after Hip Arthroplasty. Hip Pelvis. 2014; 26(4): 227-34.

54. Klouche S, Lhotellier L, Mamoudy P. Infected total hip arthroplasty treated by an irrigation-debridement/component retention protocol. A prospective study in a 12-case series with minimum 2 years' follow-up. Orthop Traumatol Surg Res. 2011; 97(2): 134-8.

55. Koyonos L, Zmistowski B, Della Valle CJ, Parvizi J. Infection control rate of irrigation and debridement for periprosthetic joint infection. Clin Orthop Relat Res. 2011; 469(11): 3043-8.

56. Vilchez F, Martinez-Pastor JC, Garcia-Ramiro S, Bori G, Tornero E, Garcia E, et al. Efficacy of debridement in hematogenous and early post-surgical prosthetic joint infections. Int J Artif Organs 2011; 34(9): 863-9.

57. Zhang C, Yan CH, Chan PK, Ng FY, Chiu KY. Polyethylene Insert Exchange Is Crucial in Debridement for Acute Periprosthetic Infections following Total Knee Arthroplasty. J Knee Surg 2017; 30(1): 36-41.

58. Fukagawa S, Matsuda S, Miura H, Okazaki K, Tashiro Y, Iwamoto Y. High-dose antibiotic infusion for infected knee prosthesis without implant removal. J Orthop Sci. 2010; 15(4): 470-6.

59. Geurts JA, Janssen DM, Kessels AGH, Walenkamp GH. Good results in postoperative and hematogenous deep infections of 89 stable total hip and knee replacements with retention of prosthesis and local antibiotics. Acta Orthop. 2013; 84(6): 509-16.

60. Peel TN, Buising KL, Dowsey MM, Aboltins CA, Daffy JR, Stanley PA, et al. Outcome of debridement and retention in prosthetic joint infections by methicillin-resistant staphylococci, with special reference to rifampin and fusidic acid combination therapy. Antimicrob Agents Chemother. 2013; 57(1): 350-5

61. Puhto AP, Syrjala H. Short-course antibiotics for prosthetic joint infections treated with prosthesis retention. Clin Microbiol Infect. 2012; 18(11): 1143-8.

62. Chung JY, Ha CW, Park YB, Song YJ, Yu KS. Arthroscopic debridement for acutely infected prosthetic knee: any role for infection control and prosthesis salvage? Arthroscopy. 2014; 30(5): 599-606.

63. Waldman BJ, Hostin E, Mont MA, - MMF, Hungerford DS. Infected total knee arthroplasty treated by arthroscopic irrigation and debridement. J Arthroplasty 2000; 15(4): 430-6.
64. Kalteis T, Lehn N, Schroder H-J, Schubert T, Zysk S, Handel M, et al. Contaminant seeding in bone by different irrigation methods: an experimental study. J Orthop Trauma 2005; 19(9): 591-6.

65. Munoz-Mahamud E, Garcia S, Bori G, Martinez-Pastor JC, Zumbado JA, Riba J, et al. Comparison of a low-pressure and a high-pressure pulsatile lavage during debridement for orthopaedic implant infection. Arch Orthop Trauma Surg 2011; 131(9): 1233-8

66. Anglen JO, Apostoles S, Christensen G, Gainor B. The efficacy of various irrigation solutions in removing slime-producing Staphylococcus. J Orthop Trauma 1994; 8(5): 390-6.

67. Bartoszewicz M, Rygiel A, Krzeminski M, Przondo-Mordarska A. Penetration of a selected antibiotic and antiseptic into a biofilm formed on orthopedic steel implants. Ortop Traumatol Rehabil 2007; 9(3): 310-8.

68. Moussa FW, Gainor BJ, Anglen JO, Christensen G, Simpson WA. Disinfecting agents for removing adherent bacteria from orthopaedic hardware. Clin Orthop Relat Res 1996 Aug;(329): 255-62.

69. Smith DC, Maiman R, Schwechter EM, Kim SJ, Hirsh DM. Optimal Irrigation and Debridement of Infected Total Joint Implants with Chlorhexidine Gluconate. J Arthroplasty. 2015; 30(10): 1820-2.

70. Schwechter EM, Folk D, Varshney AK, Fries BC, Kim SJ, Hirsh DM. Optimal irrigation and debridement of infected joint implants: an in vitro methicillin-resistant Staphylococcus aureus biofilm model. J Arthroplasty. 2011; 26(6 Suppl): 109-13.

71. Bjarnsholt T, Alhede M, Jensen PO, Nielsen AK, Johansen HK, Homoe P, et al. Antibiofilm Properties of Acetic Acid. Adv Wound Care (New Rochelle). 2015; 4(7): 363-72.

72. Williams RL, Ayre WN, Khan WS, Mehta A, Morgan-Jones R. Acetic Acid as Part of a Debridement Protocol During Revision Total Knee Arthroplasty. LID - S0883-5403(16)30652-0 [pii] LID 10.1016/j.arth.2016.09.010 [doi]. J Arthroplasty. 2016.

73. Whiteside LA, Peppers M, Nayfeh TA, Roy ME. Methicillin-resistant Staphylococcus aureus in TKA treated with revision and direct intra-articular antibiotic infusion. Clin Orthop Relat Res. 2011; 469(1): 26-33.

74. Whiteside LA, TA N, LaZear R, Roy ME. Reinfected revised TKA resolves with an aggressive protocol and antibiotic infusion. Clin Orthop Relat Res. 2012; 470(1): 236-43.

75. Whiteside LA, Roy ME. One-stage Revision With Catheter Infusion of Intraarticular Antibiotics Successfully Treats Infected THA. Clin Orthop Relat Res. 2017; 475(2): 419-29.

76. Tintle SM, Forsberg JA, Potter BK, Islinger RB, Andersen RC. Prosthesis retention, serial debridement, and antibiotic bead use for the treatment of infection following total joint arthroplasty. Orthopedics. 2009; 32(2)

77. Tornero E, Morata L, Martinez-Pastor JC, Angulo S, Combalia A, Bori G, et al. Importance of selection and duration of antibiotic regimen in prosthetic joint infections treated with debridement and implant retention. J Antimicrob Chemother. 2016; 71(5): 1395-401.

78. Zimmerli W, Widmer AF, Blatter M, Frei R, Ochsner PE. Role of rifampin for treatment of orthopedic implant-related staphylococcal infections: a randomized controlled trial. Foreign-Body Infection (FBI) Study Group. JAMA. 1998; 279(19): 1537-41.

79. Lora-Tamayo J, Murillo O, Iribarren JA, Soriano A, Sanchez-Somolinos M, Baraia-Etxaburu JM, et al. A large multicenter study of methicillin-susceptible and methicillin-resistant Staphylococcus aureus prosthetic joint infections managed with implant retention. Clin Infect Dis. 2013; 56(2): 182-94.

80. Morata L, Senneville E, Bernard L, Nguyen S, Buzele R, Druon J, et al. A Retrospective Review of the Clinical Experience of Linezolid with or Without Rifampicin in Prosthetic Joint Infections Treated with Debridement and Implant Retention. Infect Dis Ther. 2014; 3(2): 235-43.

81. Vilchez F, Martinez-Pastor JC, Garcia-Ramiro S, Bori G, Macule F, Sierra $\mathrm{J}$, et al. Outcome and predictors of treatment failure in early post-surgical prosthetic joint infections due to Staphylococcus aureus treated with debridement. Clin Microbiol Infect. 2011; 17(3): 439-44.

82. Achermann Y, Eigenmann K, Ledergerber B, Derksen L, Rafeiner P, Clauss $M$, et al. Factors associated with rifampin resistance in staphylococcal periprosthetic joint infections (PJI): a matched case-control study. Infection 2013; 41(2).

83. Grossi O, Asseray N, Bourigault C, Corvec S, Valette M, Navas D, et al. Gram-negative prosthetic joint infections managed according to a multidisciplinary standardized approach: risk factors for failure and outcome with and without fluoroquinolones. J Antimicrob Chemother. 2016; 71(9): 2593-7.

84. Tanaka G, Shigeta M, Komatsuzawa H, Sugai M, Suginaka H, Usui T. Effect of the growth rate of Pseudomonas aeruginosa biofilms on the susceptibility to antimicrobial agents: beta-lactams and fluoroquinolones. Chemotherapy 1999; 45(1): 28-36.

85. Lora-Tamayo J, Euba G, Cobo J, Horcajada JP, Soriano A, Sandoval E, et al. Short- versus long-duration levofloxacin plus rifampicin for acute 
staphylococcal prosthetic joint infection managed with implant retention: a randomised clinical trial. Int J Antimicrob Agents. 2016; 48(3): 310-6.

86. Piso RJ, Elke R. Antibiotic treatment can be safely stopped in asymptomatic patients with prosthetic joint infections despite persistent elevated C-reactive protein values. Infection 2010; 38(4): 293-6.

87. Bejon P, Byren I, Atkins BL, Scarborough M, Woodhouse A, McLardy-Smith P, et al. Serial measurement of the C-reactive protein is a poor predictor of treatment outcome in prosthetic joint infection. J Antimicrob Chemother. 2011; 66(7): 1590-3.

88. Jimenez-Garrido CA-Ohoo, Gomez-Palomo JM, Rodriguez-Delourme I, Duran-Garrido FJ, Nuno-Alvarez E, Montanez-Heredia E. The Kidney, Liver, Index surgery and $\mathrm{C}$ reactive protein score is a predictor of treatment response in acute prosthetic joint infection. Int Orthop 2018; 42(1): 33-8.

89. Lowik CAM, Jutte PC, Tornero E, Ploegmakers JJW, Knobben BAS, de Vries AJ, et al. Predicting Failure in Early Acute Prosthetic Joint Infection Treated With Debridement, Antibiotics, and Implant Retention: External Validation of the KLIC Score. J Arthroplasty. 2018: Mar 27. pii: S0883-5403(18)30299-7. doi: 10.1016/j.arth.2018.03.041.

90. Moojen DJ, Zwiers JH, Scholtes VAB, Verheyen CCPM, Poolman RW. Similar success rates for single and multiple debridement surgery for acute hip arthroplasty infection. Acta Orthop. 2014; 85(4): 383-8.

91. Brimmo O, Ramanathan D, Schiltz NK, Pillai AL, Klika AK, Barsoum WK. Irrigation and Debridement Before a 2-Stage Revision Total Knee Arthroplasty Does Not Increase Risk of Failure. J Arthroplasty. 2016; 31(2): 461-4.

92. Wang X, Sadovskaya I, Leterme D, Watier D, Chokr A, Zhu Za, et al. A comparative study of antibodies against proteins extracted from staphylococcal biofilm for the diagnosis of orthopedic prosthesis-related infections in an animal model and in humans. Diagn Microbiol Infect Dis 2013; 75(2): 124-9.

93. Parvizi J, Alijanipour P, Barberi EF, Hickok NJ, Phillips KS, Shapiro IM, et al. Novel developments in the prevention, diagnosis, and treatment of periprosthetic joint infections. J Am Acad Orthop Surg. 2015; 23 Suppl: S32-43.

94. Costa F, Maia S, Gomes J, Gomes P, Martins MC. Characterization of hLF1-11 immobilization onto chitosan ultrathin films, and its effects on antimicrobial activity. Acta Biomater. 2014; 10(8): 3513-21.

95. Sousa R, Silva M, Sousa A, Esteves J, Neves P, Seabra-Lopes J, et al. Treatment of Prosthetic Joint Infections with Debridement and Implant Retention -results of prospectively aplying a predetermined protocol [in portuguese]. Rev Port Ortop Traumatol. 2017; 25(I): 16-27. 